Sains Malaysiana 49(4)(2020): 953-962

http://dx.doi.org/10.17576/jsm-2020-4904-24

\title{
Using Hybrid of Block-Pulse Functions and Bernoulli Polynomials to Solve Fractional Fredholm-Volterra Integro-Differential Equations
}

(Menggunakan Fungsi Blok-Denyut Hibrid dan Polinomial Bernoulli untuk Menyelesaikan Persamaan PembezaanIntegro Fredholm-Volterra Pecahan)

\author{
ABBAS SAADATMANDI* \& SAMIYE AKHLAGHI
}

\section{ABSTRCT}

Fractional integro-differential equations have been the subject of significant interest in science and engineering problems. This paper deals with the numerical solution of classes of fractional Fredholm-Volterra integro-differential equations. The fractional derivative is described in the Caputo sense. We consider a hybrid of block-pulse functions and Bernoulli polynomials to approximate functions. The fractional integral operator for these hybrid functions together with the Legendre-Gauss quadrature is used to reduce the computation of the solution of the problem to a system of algebraic equations. Several examples are given to show the validity and applicability of the proposed computational procedure.

Keywords: Bernoulli polynomials; Block-pulse functions; fractional integro-differential equations; hybrid functions; Caputo derivative

\section{ABSTRACK}

Persamaan pembezaan integro pecahan telah menjadi subjek penting dalam masalah sains dan kejuruteraan. Makalah ini berkaitan dengan penyelesaian berangka kelas persamaan pembezaan integro Fredholm-Volterra pecahan. Terbitan pecahan diterangkan dalam maksud Caputo. Fungsi hibrid blok-denyutan dan polinomial Bernoulli dipertimbangkan untuk penghampiran fungsi. Pengoperasi kamiran pecahan untuk fungsi hibrid bersama-sama dengan kuadratur Legendre-Gauss digunakan untuk mengurangkan pengiraan penyelesaian masalah kepada sistem persamaan algebra. Beberapa contoh diberikan untuk menunjukkan kesahihan dan kebolehgunaan prosedur pengiraan yang dicadangkan.

Kata kunci: Fungsi blok-denyutan; fungsi hibrid; persamaan pembezaan integro pecahan; polinomial Bernoulli; terbitan Caputo

\section{INTRODUCTION}

The study of the fractional derivative has its origins in 1695. Leibniz and L'Hospital can be considered as the first two mathematics to discuss on fractional derivative (Kilbas et al. 2006). In recent years, the study of fractional differential equations and fractional integro-differential equations (FIDEs) has gained high interest because of its considerable application in science and engineering (Abdullah 2013; Abuasad \& Hashim 2018; Dascioglu \& Bayram 2019; Kilbas et al. 2006; Miller \& Ross 1993; Podlubny 1999; Saadatmandi \& Dehghan 2011a, 2011b). FIDEs occur in many physical processes such as chemistry, electromagnetism, acoustics, and viscoelastic materials (Kilbas et al. 2006; Miller \& Ross 1993; Podlubny 1999). Unfortunately, analytic solutions of the most FIDEs cannot be obtained explicitly, therefore, numerical techniques must be used. In the past two decades or so, considerable numerical methods to solve FIDEs have been given such as collocation method (Rawashdeh 2006; Saadatmandi \& Dehghan 2011a; Saadatmandi et al. 2018), Adomian's decomposition method (Mittal \& Nigam 2008; Momani
\& Noor 2006), variational iteration method (Kurulay \& Secer 2011), fractional differential transform method (Arikoglu \& Ozkol 2009), modification of hat functions (Nemati \& Lima 2018), hybrid functions (Mashayekhi \& Razzaghi 2015), Taylor expansion method (Huang et al. 2011), Sinc-collocation method (Bayram et al. 2018) and the wavelet method (Meng et al. 2015; Saeedi et al. 2011; Zhu \& Fan 2012).

In this paper, we study the numerical solution of following fractional Fredholm-Volterra integrodifferential equation (Rahimkhani et al. 2017)

$$
\begin{gathered}
D^{v} y(x)=\lambda y(x)+g(x)+\lambda_{1} \int_{0}^{x} k_{1}(x, t)[y(t)]^{q^{1}} \\
\left.D^{v_{1}} y(t)\right]^{q_{2}} d t+\lambda_{2} \int_{0}^{1} k_{2}(x, t)[y(t)]^{q_{3}} \\
{\left[D^{v_{2}} y(t)\right]^{q_{4}} d t,}
\end{gathered}
$$

$$
0 \leq x, t \leq 1, n-1<v \leq n, 0 \leq v_{1} v_{2} \leq v
$$


with initial conditions

$$
y^{(k)}(0)=\mu_{k}, k=0,1, \ldots, n-1 .
$$

Wherever, the mentioned functions $g, k_{1}$ and $k_{2}$ are realvalued functions. Also, $k 1$, and $k_{2}$ are assumed to be separable kernels. In addition, $\lambda, \lambda_{1}, \lambda_{2}, \mu_{k}, k=0,1, \ldots, n$ - 1 are real given numbers and $q_{i}, i=1, \ldots, 4$, are positive integers. Here, $D^{v}, D^{v_{1}}$ and $D^{v_{2}}$ are the Caputo type fractional derivatives of order $v, v_{1}$ and $v_{2}$ respectively.

The literature of numerical methods contains little on the solutions of (1). Rahimkhani et al. (2017) used fractional-order Bernoulli functions for solving (1). Also, for the case of $q_{2}=q_{4}=0$, Keshavarz et al. (2019) applied Bernoulli wavelets to approximate solutions of (1). Moreover, Meng et al. (2015) used the Legendre wavelets method to solve (1) with $\lambda=q_{2}=q_{4}=0$ and $q_{1}=q_{3}=1$.

The main idea of this work is to apply a hybrid of block-pulse functions and Bernoulli polynomials together with the collocation method to solve the problem (1)-(2). The main advantage behind this approach is that it reduces the solution of fractional FredholmVolterra integro-differential (1) to those of solving a system of algebraic equations thus seriously simplifying the problem. Numerical methods based on the hybrid functions of block-pulse and Bernoulli polynomials are a nice and powerful approach for the numerical solution of problems arising from engineering applications including optimal control of delay systems (Haddadi et al. 2012), nonlinear constrained optimal control problems (Mashayekhi et al. 2012), fractional Volterra integro-differential equations (Mashayekhi \& Razzaghi 2015), multi-delay systems (Mashayekhi et al. 2016) and fractional Bagley-Torvik equation (Mashayekhi \& Razzaghi 2016).

This paper is organized in the following way: in the next section, some basic results of fractional calculus and some properties of the hybrid of block-pulse functions and Bernoulli polynomials required for our subsequent development are given. In subsequent section, the new method proposed in this paper is presented. In the following section, some numerical results are given to clarify the method. Last section contains a brief conclusion.

\section{PRELIMINARIES AND NOTATIONS}

\section{THE FRACTIONAL DERIVATIVE AND INTEGRAL}

Definition 2.1 The Riemann-Liouville fractional integral of order $\alpha$ is defined as (Podlubny 1999)

$$
I^{\alpha} f(t)=\left\{\begin{array}{cc}
\frac{1}{\Gamma(\alpha)} \int_{0}^{t}(t-s)^{\alpha-1} f(s) d s, & \alpha>0, \\
f(t), & \alpha=0,
\end{array}\right.
$$

Definition 2.2 The Caputo fractional derivative with order $\alpha>0$ is defined by (Podlubny 1999)

$$
D^{\alpha} f(t)=\left\{\begin{array}{cc}
\frac{1}{\Gamma(n-\alpha)} \int_{0}^{t} \frac{f^{(n)}(\tau)}{(t-\tau)^{\alpha+1-n}} d \tau, & n-1<\alpha<n, n \in \mathbb{N}, \\
\frac{d^{n}}{d t^{n}} f(t), & \alpha=n \in \mathbb{N} .
\end{array}\right.
$$

We have the following properties (Podlubny 1999):

1. $D^{\alpha} C=0 \quad(C$ is a constant $)$.

2. $D^{\alpha} t^{m}=\left\{\begin{array}{cl}0, & m<\lceil\alpha\rceil, \\ \frac{\Gamma(m+1)}{\Gamma(m+1-\alpha)} t^{m-\alpha}, & m \geq\lceil\alpha\rceil .\end{array}\right.$

where $\lceil$.$\rceil is the ceiling function and m \in \mathbf{N}$

3. $D^{\alpha}$ and $I^{\alpha}$ are linear operators.

4. $D^{\alpha} I^{\alpha} f(t)=f(t)$.

$$
\text { 5. } \begin{aligned}
I^{\alpha}\left(D^{\alpha} f(t)\right)= & f(t)-\sum_{k=0}^{n-1} f^{(k)}\left(0^{+}\right) \frac{t^{k}}{k !}, \\
& n-1<\alpha \leq n, n \in \mathrm{N}, t>0 .
\end{aligned}
$$

6. $D^{\alpha} f(t)=I^{m-\alpha} D^{m} f(t), \quad m \in \mathbf{N}$

\section{HYBRID OF BLOCK-PULSE FUNCTIONS AND BERNOULL POLYNOMIALS}

The well-known Bernoulli polynomials of the order $m$ are defined in the interval $[0,1]$ with the following formula (Costabile et al. 2006)

$$
\beta_{m}(t)=\sum_{k=0}^{m}\left(\begin{array}{l}
m \\
k
\end{array}\right) \alpha_{k} t^{m-k},
$$

where Bernoulli numbers $\alpha_{k}$, can be defined by Costabile et al. (2006)

$$
\frac{t}{e^{t}-1}=\sum_{n=0}^{\infty} \alpha_{n} \frac{t^{n}}{n !}
$$

The Bernoulli numbers $\alpha_{k}$ are rational numbers and the first few are

$$
\alpha_{0}=1, \alpha_{1}=\frac{-1}{2}, \alpha_{2}=\frac{1}{6}, \alpha_{4}=\frac{-1}{30}, \alpha_{6}=\frac{1}{42} .
$$

It can be shown that $\alpha_{2 k+1}=0$ for $k \geq 1$. Now, hybrid functions $b_{n m}(t), n=1,2, \ldots, N, m=0,1, \ldots, M$, are defined on the interval $[0,1]$ as (Mashayekhi et al. 2012)

where $\Gamma($.$) is the Gamma function.$ 


$$
b_{n m}(t)=\left\{\begin{array}{cc}
\beta_{m}(N t-n+1), & t \in\left[\frac{n-1}{N}, \frac{n}{N}\right) . \\
0, & \text { otherwise. }
\end{array}\right.
$$

Here, $m$ and $n$ are the order of Bernoulli polynomials and block-pulse functions, respectively.

\section{Function approximation and error estimation}

Let $H=L^{2}[0,1]$. . We define the approximation space as $Y=\operatorname{span}\left\{b_{10}(t), b_{20}(t), \ldots, b_{N 0}(t), b_{11}(t), b_{21}(t), \ldots, b_{N 1}(t) \ldots\right.$,

$$
\left.b_{1 M}(t), \ldots, b_{N M}(t)\right\}
$$

Clearly, $Y$ is a finite-dimensional subspace of $H$, thus any function $f \in H$ has a best unique approximation out of $Y$ (Mashayekhi et al. 2012). That is, given $f \in H$ there exists $P_{M}^{N} f \in Y$ such that

$$
\left\|f-P_{M}^{N} f\right\| \leq\|f-y\|,
$$

for all $\mathrm{y} \in Y$. Therefore, there exist unique coefficients $c_{10}, c_{20}, \ldots, c_{N M}$ such that

$$
f \simeq P_{M}^{N} f=\sum_{m=0}^{M} \sum_{n=1}^{N} c_{n m} b_{n m}(t)=C^{T} B(t),
$$

where

$$
C=\left[c_{10}, \ldots, c_{N 0}, c_{11}, \ldots, c_{N 1}, \ldots, c_{1 M}, \ldots, c_{N M}\right]^{T},
$$

and

$$
\begin{aligned}
B(t)= & {\left[b_{10}(t), \ldots, b_{N 0}(t), b_{11}(t), \ldots, b_{N 1}(t), \ldots, b_{1 M}(t), \ldots,\right.} \\
& \left.b_{N M}(t)\right]^{T} .
\end{aligned}
$$

The following error bound was proved in (Mashayekhi et al. 2016).

Theorem 2.3 Suppose $f \in H^{\mu}[0,1]$ with $\mu 0$, and $M \geq$ $\mu-1$, then

$$
\left\|f-P_{M}^{N} f\right\|_{L^{2}[0,1]} \leq c M^{-\mu} N^{-\mu}\left\|f^{(\mu)}\right\|_{L^{2}[0,1]}
$$

and for $r \geq 1$

$$
\left\|f-P_{M}^{N} f\right\|_{H^{r}[0,1]} \leq c M^{2 r-\frac{1}{2}-\mu} N^{r-\mu}\left\|f^{(\mu}\right\|_{L^{2}[0,1]},
$$

where $c$ depends $\mu$ on .
Riemann-Liouville fractional integral operator for $B(t)$ The fractional integration of the $B(t)$, defined in (10), is given by

$$
I B(t)=\bar{B}(t, \quad),
$$

where

$\bar{B}(t, a)=\left[I^{a} b_{10}(t), \ldots, I^{a} b_{N 0}(t), I^{a} b_{11}(t), \ldots, I^{\alpha} b_{N 1}(t)\right.$,

$\left.\ldots, I^{a} b_{1 M}(t), I^{a} b_{2 M}(t), \ldots, I^{a} b_{N M}(t)\right]^{T}$,

and $I^{\alpha} b_{n m}(t)$ is obtained from (Mashayekhi \& Razzaghi 2016, 2015)

$I^{a} b_{n m}(t)= \begin{cases}0, & t \in\left(-\infty, \frac{n-1}{N}\right), \\ \left(t-\frac{n-1}{N}\right)^{a} d_{n m}(t), & t \in\left[\frac{n-1}{N}, \frac{n}{N}\right), \\ \left(t-\frac{n-1}{N}\right)^{a} d_{n m}(t)-(-1)^{m}\left(t-\frac{n}{N}\right)^{a} \bar{d}_{n m}(t), & t \in\left[\frac{n}{N}, \infty\right),\end{cases}$

where

$$
\begin{aligned}
& d_{n m}(t)=\sum_{k=0}^{m}\left(\begin{array}{c}
m \\
k
\end{array}\right) a_{m-k} N^{k} \frac{\Gamma(k+1)}{\Gamma(k+a+1)}\left(t-\frac{n-1}{N}\right)^{k}, \\
& \bar{d}_{n m}(t)=\sum_{k=0}^{m}(-1)^{k}\left(\begin{array}{c}
m \\
k
\end{array}\right) a_{m-k} N^{k} \frac{\Gamma(k+1)}{\Gamma(k+a+1)}\left(t-\frac{n}{N}\right)^{k} .
\end{aligned}
$$

\section{LEGENDRE-GAUSS QUADRATURE}

Suppose that $\left\{\boldsymbol{\tau}_{q}\right\}_{q=0}^{n}$ are the distinct roots of the Legendre polynomial of degree $n+1$. The $(n+1)$-point LegendreGauss quadrature rule for approximating integral of a function $g(t)$ over the interval $(a, b)$, is given by (Canuto et al. 1988)

$$
\int_{a}^{b} g(t) d t \simeq \frac{b-a}{2} \sum_{q=0}^{n} \omega_{q} g\left(\sigma_{q}\right),
$$

where

$$
\begin{aligned}
\sigma_{q} & =\frac{b-a}{2} \tau_{q}+\frac{b+a}{2}, \omega_{q}=\frac{2}{\left(1-\tau_{q}^{2}\right)\left(L_{n+1}\left(\tau_{q}\right)\right)^{2}}, \\
q & =0, \ldots, n .
\end{aligned}
$$

Here, $\left\{\sigma_{q}\right\}_{q=0}^{n}$ and $\left\{w_{q}\right\}_{q=0}^{n}$ are Legendre-Gauss quadrature nodes and weights, respectively. This quadrature formula is exact for all $g(x)$ which are polynomials of at most degree $2 n+1$.

\section{SOLUTION OF THE PROBLEM (1)-(2)}

In this part, we apply hybrid of block-pulse functions and Bernoulli polynomials to approximate solutions of 
fractional Fredholm-Volterra integro-differential equation (1)-(2). For this purpose, we let

$$
D^{v} y(x)=C^{T} B(x)
$$

Thanks to (16) and in the presence of some properties of fractional integration, we have

$$
y(x)-\sum_{k=0}^{n-1} \frac{x^{k}}{k !} y^{(k)}(0)=I^{v} D^{v} y(x)=C^{T} I^{v} B(x) .
$$

Employing (2), (11) and (17) we get

$$
y(x)=C^{T} \bar{B}(x, v)+\sum_{k=0}^{n-1} \frac{x^{k}}{k !} \mu_{k},
$$

also, using (17) we obtain

$$
\begin{aligned}
D^{v_{i}} y(x) & =D^{v_{i}}\left(\sum_{k=0}^{n-1} \frac{x^{k}}{k !} \mu_{k}\right)+C^{T} D^{v_{i}} I^{v} B(x) \\
& =\sum_{k=0}^{n-1} \frac{D^{v_{i}}\left(x^{k}\right)}{k !} \mu_{k}+C^{T} I^{v-v_{i}} B(x) \\
& =\sum_{k=\left\lceil v_{i}\right\rceil}^{n-1} \frac{t^{k-v_{i}} \mu_{k}}{\Gamma\left(k+1-v_{i}\right)}+C^{T} \bar{B}\left(x, v-v_{i}\right), \quad i=1,2 .
\end{aligned}
$$

Substituting (16), (18) and (19) into (1) gives

$$
\begin{aligned}
& C^{T} B(x)-\lambda\left(C^{T} \bar{B}(x, v)+\sum_{k=0}^{n-1} \frac{x^{k}}{k !} \mu_{k}\right)-g(x) \\
& -\lambda_{1} \int_{0}^{x} k_{1}(x, t)\left[C^{T} \bar{B}(t, v)+\sum_{k=0}^{n-1} \frac{t^{k}}{k !} \mu_{k}\right]^{q_{1}}\left[C^{T} \bar{B}\left(t, v-v_{1}\right)+\right. \\
& \left.\sum_{k=\left\lceil v_{1}\right\rceil}^{n-1} \frac{t^{k-v_{1}} \mu_{k}}{\Gamma\left(k+1-v_{1}\right)}\right]^{q_{2}} d t \\
& -\lambda_{2} \int_{0}^{1} k_{2}(x, t)\left[C^{T} \bar{B}(t, v)+\sum_{k=0}^{n-1} \frac{t^{k}}{k !} \mu_{k}\right]^{q_{3}}\left[C^{T} \bar{B}\left(t, v-v_{2}\right)\right. \\
& \left.\sum_{k=\left\lceil v_{2}\right\rceil}^{n-1} \frac{t^{k-v_{2}} \mu_{k}}{\Gamma\left(k+1-v_{2}\right)}\right]^{q_{4}} d t=0 .
\end{aligned}
$$

Now, by collocating $(20)$ at $N(M+1)$ points $x=x_{i}$ and by using Legendre-Gauss quadrature rule (14), we get

$$
\begin{aligned}
& C^{T} B\left(x_{i}\right)-\lambda\left(C^{T} \bar{B}\left(x_{i}, v\right)+\sum_{k=0}^{n-1} \frac{x_{i}^{k}}{k !} \mu_{k}\right)-g\left(x_{i}\right) \\
& -\lambda_{1} \sum_{j=0}^{n} \frac{x_{i}}{2} \omega_{j} k_{1}\left(x_{i}, z_{i j}\right)\left[C^{T} \bar{B}\left(z_{i j}, v\right)+\sum_{k=0}^{n-1} \frac{\left(z_{i j}\right)^{k}}{k !} \mu_{k}\right]^{q_{1}} \\
& \times\left[C^{T} \bar{B}\left(z_{i j}, v-v_{1}\right)+\sum_{k=\left\lceil v_{1}\right\rceil}^{n-1} \frac{\left(z_{i j}\right)^{k-v_{1}} \mu_{k}}{\Gamma\left(k+1-v_{1}\right)}\right]^{q_{2}} \\
& -\lambda_{2} \sum_{j=0}^{n} \frac{1}{2} \omega_{j} k_{2}\left(x_{i}, \bar{z}_{j}\right)\left[C^{T} \bar{B}\left(\bar{z}_{j}, v\right)+\sum_{k=0}^{n-1} \frac{\left(\bar{z}_{j}\right)^{k}}{k !} \mu_{k}\right]^{q_{3}} \\
& \times\left[C^{T} \bar{B}\left(\bar{z}_{j}, v-v_{2}\right)+\sum_{k=\left\ulcorner v_{2}\right\rceil}^{n-1} \frac{\left(\bar{z}_{j}\right)^{k-v_{2}} \mu_{k}}{\Gamma\left(k+1-v_{2}\right)}\right]^{q_{4}} \\
& =0, i=0,1, \ldots, N(M+1)-1 .
\end{aligned}
$$

Here, we use uniform collocation points

$$
x_{i}=\frac{2 i+1}{2 N(M+1)}, \quad i=0,1, \ldots, N(M+1)-1 .
$$

Also, in (21), $z_{i j}=\frac{x_{i} \tau_{j}+x_{i}}{2}, \bar{z}_{j}=\frac{\tau_{j}+1}{2}$, moreover $\omega_{j}$ and $\tau_{j}$ are Legendre-Gauss weights and nodes, respectively. Therefore, (21) generate a set of $N(M+1)$ nonlinear algebraic equations, which can be solved for the unknown vector $C$. Throughout this paper, we use Maple's fsolve command to find the unknown vector $C$ from this system of algebraic equations.

\section{NUMERICAL EXAMPLES}

In this section, we present some examples to illustrate the efficiency and validity of our method for solving the problem (1)-(2). We implemented our method in a personal computer with $3.40 \mathrm{GHz}$ Intel Core 7. Also, we use 5 -point Legendre-Gauss quadrature rule.

Example 4.1 Let us first consider the nonlinear fractional Volterra integro-differential equation (Ghazanfari et al. 2010)

$D^{v} y(x)=1+\int_{0}^{x} y(t) D^{v} y(t) d t, 0 \leq x \leq 1,0 \leq x \leq 1$,

with the initial condition $y(0)=0$.

The exact solution, when $v=1$, is $y(x)=\sqrt{2} \tan \left(\frac{\sqrt{2}}{2} x\right)$.

To solve this problem by the present method, let $D^{v} y(\mathrm{x})$

$=C^{T} B(x)$. Also, by using (18), we get $\mathrm{y}(\mathrm{x})=C^{T} B(x, v)$.

Employing (21), we obtain

$C^{T} B\left(x_{i}\right)-1-\sum_{j=0}^{n} \frac{x_{i}}{2} \omega_{j} C^{T} \bar{B}\left(z_{i j}, v\right) C^{T} B\left(z_{i j}\right)=0$,

$$
i=0,1, \ldots, N(M+1)-1 \text {. }
$$

Finally, we have $N(M+1)$ algebraic equations. By solving these equations, the unknown vector $C$ is obtained. The numerical results for $\mathrm{y}(\mathrm{x})$ with $N=1, M$ $=5$ and $v=0.7,0.8,0.9,1$ are plotted in Figure 1. From Figure 1, we see that as $v$ approaches 1, the approximate solutions converge to the exact solution. i.e. in the limit, the solution of the nonlinear fractional Volterra integrodifferential equation approaches to that of the integerorder Volterra integro-differential equation. Also, in Figure 2 the logarithmic graphs of absolute error functions are plotted for $v=1$ and for different values of $M$ and $N$. This figure illustrate that the errors decay as $M$ and $N$ increases. Moreover, in Table 1, absolute errors 
and CPU times (in seconds) by choosing $v=1, m=5$ together with $N=2,3,4$ are reported. In this table, we also compare our method with $M=5$ and different values of $N$ together with the results obtained with $M=5$ by using the fractional-order Bernoulli functions given in Rahimkhani et al. (2017).

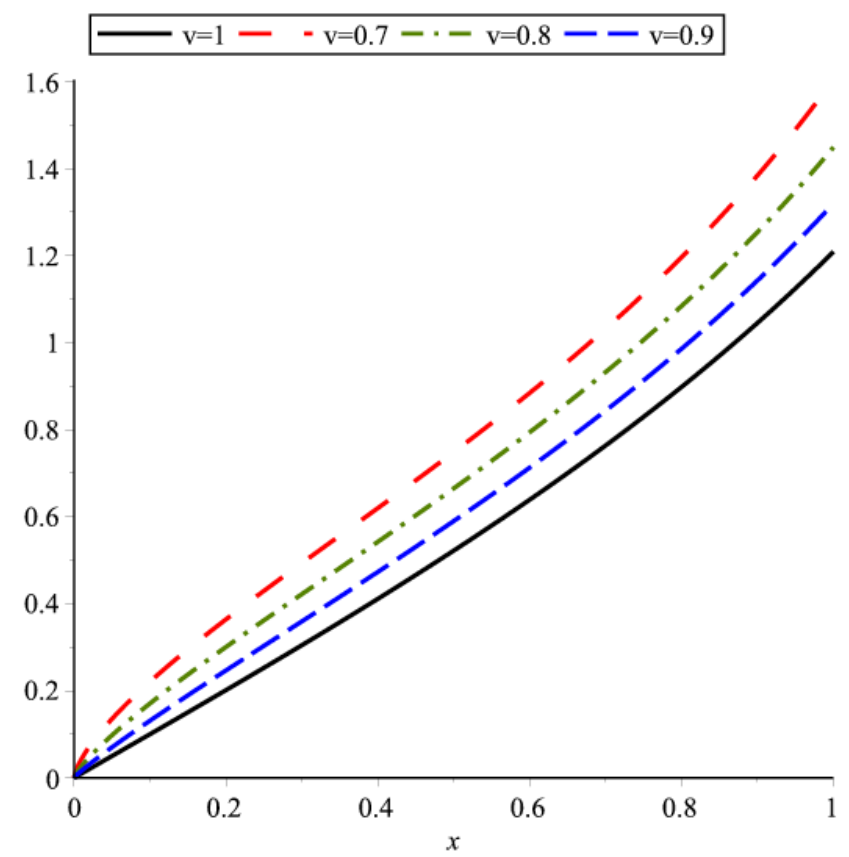

FIGURE 1. Comparison of $y(x)$ for $N=1, M=5$ and with $\mathrm{v}=0.7,0.8,0.8,1$ for Example 4.1
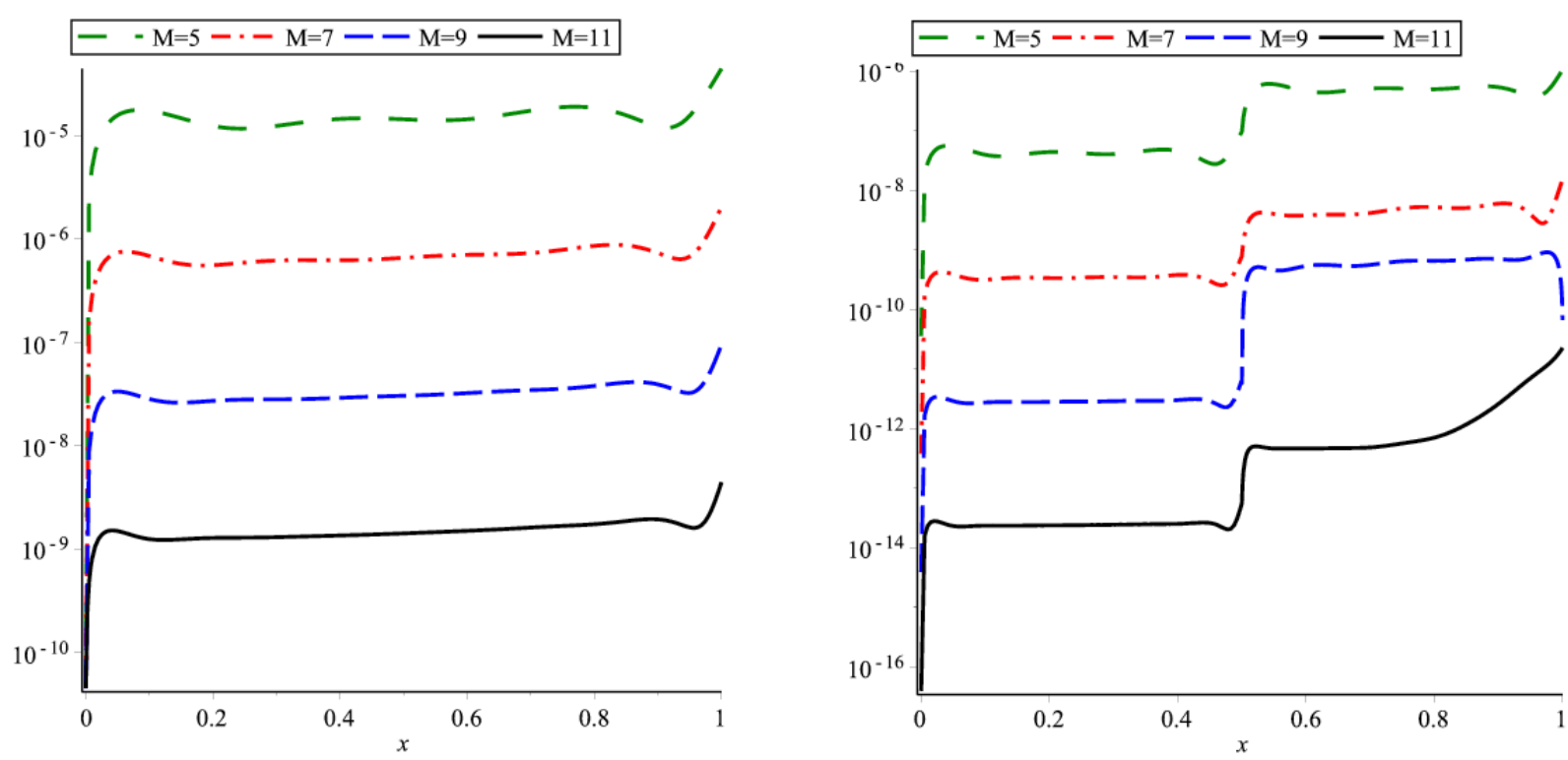

FIGURE 2. Graph of absolute error function for different values of $M$ and with $N=1$ (left) and $N=2$ (right) for Example 4.1 
TABLE 1. The comparison of absolute errors between the present method and the result given in (Rahimkhani et al. 2017) for Example 4.1

\begin{tabular}{|c|c|c|c|c|}
\hline \multirow{2}{*}{$x$} & \multirow{2}{*}{$\begin{array}{c}\text { Method of } \\
\text { (Rahimkhani et al. 2017) } \\
(M=5)\end{array}$} & \multicolumn{3}{|c|}{$\begin{array}{l}\text { Present method } \\
\qquad(M=5)\end{array}$} \\
\hline & & $N=2$ & $N=3$ & $N=4$ \\
\hline 0.2 & $5.23 \times 10-6$ & $4.43 \times 10-8$ & $1.94 \times 10-9$ & $2.65 \times 10-10$ \\
\hline 0.4 & $1.18 \times 10-6$ & $4.65 \times 10-8$ & $1.07 \times 10-8$ & $1.04 \times 10-9$ \\
\hline 0.6 & $1.00 \times 10-5$ & $5.00 \times 10-7$ & $1.19 \times 10-8$ & $3.30 \times 10-9$ \\
\hline 0.8 & $1.41 \times 10-5$ & $5.25 \times 10-5$ & $5.54 \times 10-8$ & $1.20 \times 10-8$ \\
\hline $\begin{array}{c}\mathrm{CPU} \\
\operatorname{time}(\mathrm{s})\end{array}$ & Not reported & & & \\
\hline
\end{tabular}

Example 4.2 Consider the nonlinear fractional Fredholm integro-differential equation given in Zhu dan Fan (2012) by

$$
\begin{aligned}
& D^{v} y(x)=1-\frac{x}{4}+\int_{0}^{1} x t[y(t)]^{2} d t, \quad 0 \leq x<1, \\
& 0 \leq x<1, \quad 0<v \leq 1
\end{aligned}
$$

with the initial condition $y(0)=0$

The exact solution, when $v=1$, is $y(x)=x$. According to $(21)$, we obtain
$C^{T} B\left(x_{i}\right)-1+\frac{x_{i}}{4}-\sum_{j=0}^{n} \frac{x_{i}}{2} \omega_{j} \bar{z}_{j}\left[C^{T} \bar{B}\left(\bar{z}_{j}, v\right)\right]^{2}=0, i=0,1, \ldots$, $N(M+1)-1$,

which is a nonlinear system of algebraic equations. By solving this system we can obtain the unknown vector $C$. The numerical results for $N=1, M=5$ and for different values of $v$ are shown in Figure 3. Once again, from Figure 3, we see that as $v \rightarrow 1$, the approximate solutions converges to the exact solution. Not that, for $v=1$, By choosing, $M=N=1$ we get the exact solution. However, with the technique presented in Zhu and Fan (2012), the exact solution cannot be obtained. In addition, for $v=1$, the $C P U$ time of our method is 0.904 second.

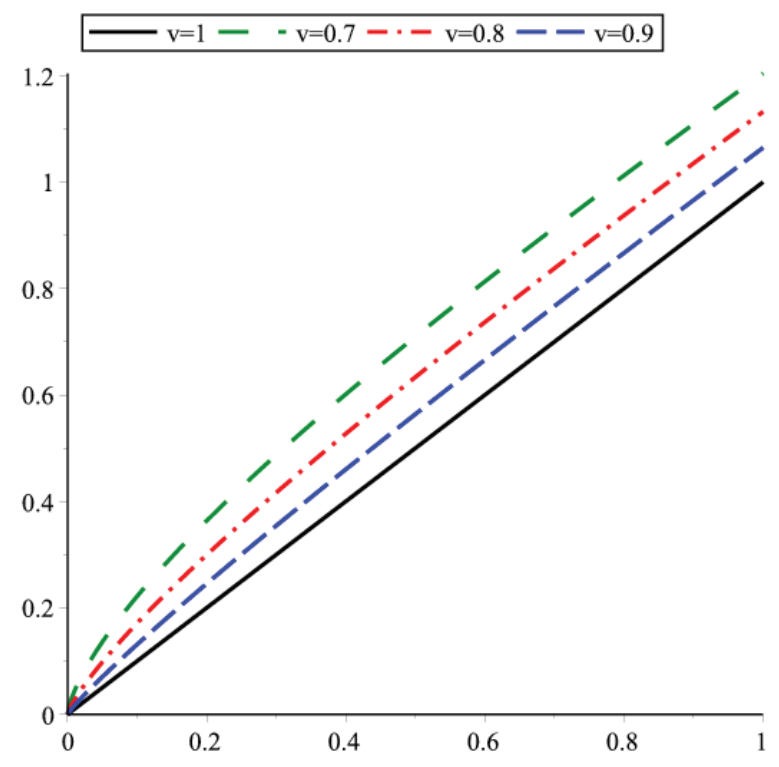

FIGURE 3. Comparison of $y(x)$ for $N=1, M=5$ and with $v=0.7,0.8,0.9,1$ for Example 4.2 
Example 4.3 Consider the following fractional mixed Fredholm-Volterra integro-differential equation (Meng et al. 2015)

$$
D^{2.3} y(x)=g(x)+\frac{1}{4} \int_{0}^{x}(x-t) y(t) d t+\frac{1}{2} \int_{0}^{1} x t y(t) d t,
$$

$0 \leq x \leq 1$

with the initial conditions $y(0)=y^{\prime}(0)=y^{\prime \prime}(0)=0$, and $g(x)=\frac{\Gamma(4.5)}{\Gamma(2.2)} x^{1.2}-\frac{1}{99} x^{5.5}-\frac{1}{11} x$.

The exact solution is $y(x)=x^{2}$. For this problem, (21), generate the following linear system of algebraic equations:

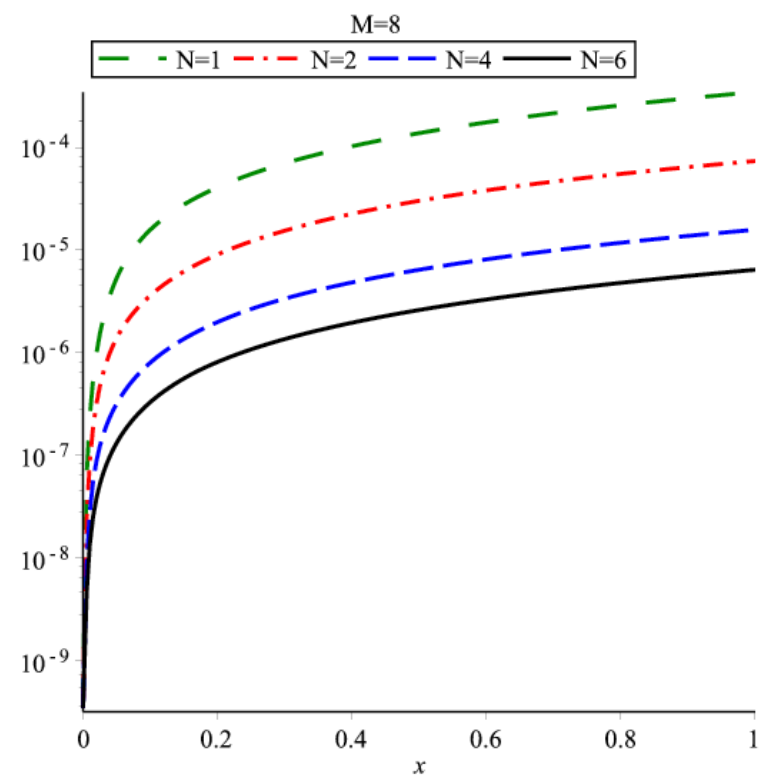

$C^{T} B\left(x_{i}\right)-g\left(x_{i}\right)-\frac{1}{8} \sum_{j=0}^{n} x_{i} \omega_{j}\left(x_{i}-z_{i j}\right) C^{T} \bar{B}\left(z_{i j}, 2.3\right)-\frac{1}{4}$

$\sum_{j=0}^{n} x_{i} \omega_{j} \bar{z}_{j} C^{T} \bar{B}\left(\bar{z}_{j}, 2.3\right)=0, \quad i=0,1, \ldots, N(M+1)-1$.

In Figure 4, the logarithmic graphs of absolute error functions are plotted for various values of $M$ and $N$. From this figure, we can find that the errors decay as $M$ and $N$ increases. Moreover, for the purpose of comparison, in Table 2 we compare the absolute error of our method with $N=2$ and different values of $M$ together with the results obtained by using Adomian decomposition method (ADM) and the Legendre wavelets method (LWM) given in Meng et al. (2015). In addition, in Table 2, the CPU times of our method are reported.

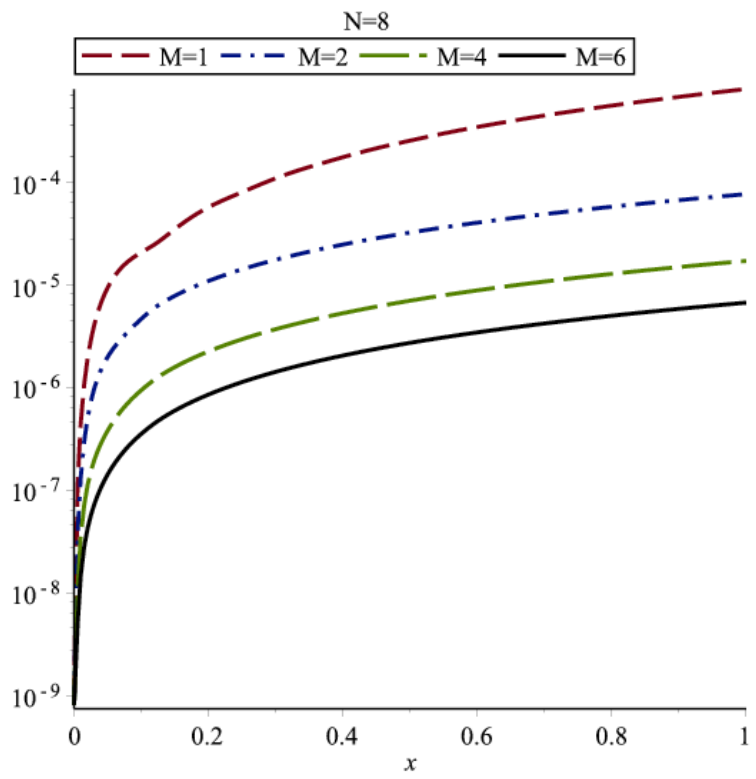


TABLE 2. The comparison of absolute errors at some points for the present method and the result given in (Meng et al. (2015) for Example 4.3

\begin{tabular}{cccccc}
\hline & \multicolumn{3}{c}{ LWM } & \multicolumn{3}{c}{ Present method } \\
\cline { 2 - 5 } & $m=2, k=4$ & $m=2, k=5$ & $n=5$ & $M=6, N=2$ & $M=7, N=2$ \\
\hline $1 / 8$ & $4.87 \times 10^{-5}$ & $6.64 \times 10^{-5}$ & $1.02 \times 10^{-5}$ & $9.89 \times 10^{-6}$ & $6.76 \times 10^{-6}$ \\
$2 / 8$ & $8.92 \times 10^{-5}$ & $4.53 \times 10^{-5}$ & $4.20 \times 10^{-5}$ & $2.47 \times 10^{-5}$ & $1.69 \times 10^{-5}$ \\
$3 / 8$ & $7.09 \times 10^{-5}$ & $3.14 \times 10^{-5}$ & $9.24 \times 10^{-5}$ & $4.21 \times 10^{-5}$ & $2.89 \times 10^{-5}$ \\
$4 / 8$ & $2.36 \times 10^{-4}$ & $7.37 \times 10^{-5}$ & $4.17 \times 10^{-4}$ & $6.15 \times 10^{-5}$ & $4.20 \times 10^{-5}$ \\
$5 / 8$ & $7.11 \times 10^{-4}$ & $2.44 \times 10^{-4}$ & $8.16 \times 10^{-4}$ & $8.16 \times 10^{-5}$ & $5.70 \times 10^{-5}$ \\
$6 / 8$ & $2.51 \times 10^{-3}$ & $3.81 \times 10^{-4}$ & $2.31 \times 10^{-3}$ & $1.03 \times 10^{-4}$ & $7.30 \times 10^{-5}$ \\
$7 / 8$ & $3.04 \times 10^{-3}$ & $6.02 \times 10^{-4}$ & $8.07 \times 10^{-3}$ & $1.25 \times 10^{-4}$ & $9.02 \times 10^{-5}$ \\
\hline $\begin{array}{c}\text { CPU } \\
\text { time(s) }\end{array}$ & Not reported & Not reported & Not reported & 0.530 & 0.546 \\
\hline
\end{tabular}

Example 4.4 Consider the following nonlinear fractional mixed Fredholm-Volterra integro-differential equation (Meng et al. 2015)

$D^{2.2} y(x)=g(x)+\frac{1}{3} \int_{0}^{x}(x+t)[y(t)]^{2} d t+\frac{1}{4} \int_{0}^{1}$

$(x-t)[y(t)]^{3} d t, 0 \leq x \leq 1$,

with the initial conditions $y(0)=y^{\prime}(0)=y^{\prime \prime}(0)=0$ and

$$
g(x)=\frac{\Gamma(4)}{\Gamma(1.8)} x^{0.8}-\frac{5}{56} x^{8}-\frac{1}{40} x+\frac{1}{44} .
$$

The exact solutin of this problem is $y(x)=x^{3}$. Here, (21), generate the following $m=N(M+1)$ nonlinear system of algebraic equations:

$$
\begin{aligned}
& C^{T} B\left(x_{i}\right)-g\left(x_{i}\right)-\frac{1}{6} \sum_{j=0}^{n} x_{i} \omega_{j}\left(x_{i}+z_{i j}\right)\left[C^{T} \bar{B}\left(z_{i j}, 2.2\right)\right] \\
& -\frac{1}{8} \sum_{j=0}^{n}\left(x_{i}-\bar{z}_{j}\right) \omega_{j}\left[C^{T} \bar{B}\left(\bar{z}_{j}, 2.2\right)\right]^{3} \\
& =0, \quad i=0,1, \ldots, N(M+1)-1 .
\end{aligned}
$$

For the purpose of comparison of our method with the Legendre wavelets method (LWM) and CAS wavelet method (CASW) given in (Meng et al. 2015) we define $l_{\infty}$ norm of absolute errors by

$$
\left\|e_{m}\right\|_{\infty}=\max _{1 \leq i \leq m}\left\{\left|y\left(x_{i}\right)-y_{m}\left(x_{i}\right)\right|\right\},
$$

where $y$ is the exact solution; and $y_{m}$ is the approximate solution. The results are summarized in Table 3. Also, in Table 3, the CPU times of our method are reported.

\begin{tabular}{|c|c|c|c|c|c|c|}
\hline & \multicolumn{2}{|c|}{ LWM } & \multicolumn{2}{|c|}{ CASW } & \multicolumn{2}{|c|}{ Present method } \\
\hline & $m=16$ & $m=32$ & $m=16$ & $m=32$ & $\begin{array}{c}m=9 \\
(M=8, N=1)\end{array}$ & $\begin{array}{c}m=20 \\
(M=9, N=2)\end{array}$ \\
\hline$\left\|e_{m}\right\|_{\infty}$ & $4.43 \times 10-3$ & $2.14 \times 10-3$ & $7.84 \times 10-2$ & $5.24 \times 10-3$ & $7.85 \times 10-4$ & $1.89 \times 10-4$ \\
\hline $\begin{array}{c}\text { CPU } \\
\text { Time(s) }\end{array}$ & 0.823 & 2.427 & \multicolumn{2}{|c|}{ Not reported } & 0.515 & 2.434 \\
\hline
\end{tabular}
According to Table 3, we find that the presented method provides accurate results.

TABLE 3. A comparison of $\left\|e_{m}\right\|_{\infty}$ between the present method and the result given in Meng et al. (2015) for Example 4.4 
As an another approach to this problem, we choose $N=$ 1 and $M=0$. Let

$$
D^{3} y(x)=C^{T} B(x)=c_{10} b_{10}(x),
$$

thus similar to (17) we get

$y(x)=C^{T} \bar{B}(x, 3)=c_{10} I^{3} b_{10}(x)$.

Also, by using (31), we obtain

$$
D^{2.2} y(x)=C^{T} \bar{B}(x, 0.8)=c_{10} I^{0.8} b_{10}(x) .
$$

Substituting (31) and (32) in (29) and applying the Legendre-Gauss quadrature, we have

$$
\begin{aligned}
& c_{10} I^{0.8} b_{10}\left(x_{0}\right)-g\left(x_{0}\right)-\frac{1}{6} \sum_{j=0}^{n} x_{0} \omega_{j}\left(x_{0}+z_{0 j}\right)\left[c_{10} I^{3} b_{10}\right. \\
& \left.\left(z_{0 j}\right)\right]^{2}-\frac{1}{8} \sum_{j=0}^{n} \omega_{j}\left(x_{0}-\bar{z}_{j}\right)\left[c_{10} I^{3} b_{10}\left(\bar{z}_{j}\right)\right]^{3}=0
\end{aligned}
$$

where $x_{0}=1 / 2$ is a collocation point. By solving this equation we get $C_{10}=6$. Thus, using (31), we get $y(x)=$ $x^{3}$, which is the exact solution of the problem.

\section{CONCLUSION}

In this paper, a collocation method with a hybrid of blockpulse functions and Bernoulli polynomials is successfully used to solve a class of fractional Fredholm-Volterra integro-differential equations. The method is easy to implement, and applications are demonstrated through several illustrative examples. The numerical results are in excellent agreement with those obtained in Meng et al. (2015) and Rahimkhani et al. (2017). Note that we have computed the numerical results using the Maple package.

\section{REFERENCES}

Akhriadi, F.A. 2013. Simulations of Hirschsprung's disease using fractional differential equation. Sains Malaysiana 42(5): 661-666.

Abuasad, S. \& Hashim, I. 2018. Homotopy decomposition method for solving higher-order time-fractional diffusion equation via modified beta derivative. Sains Malaysiana 47(11): 2899-2905.

Arikoglu, A. \& Ozkol, I. 2009. Solution of fractional integrodifferential equations by using fractional differential transform method. Chaos, Solitons and Fractals 40: 521-529.

Bayram, M., Hatipoglu, V.F., Alkan, S. \& Das, S.E. 2018. A solution method for integro-differential equations of conformable fractional derivative. Thermal Science 22: S7-S14.

Canuto, C., Hussaini, M.Y., Quarteroni, A. \& Zang, T.A. 1988. Spectral Methods in Fluid Dynamic. Englewood Cliffs, NJ: Prentice-Hall

Costabile, F., Dellaccio, F. \& Gualtieri, M.I. 2006. A new approach to Bernoulli polynomials. Rendiconti di Matematica Serie VII 26: 1-12.
Dascioglu, A. \& Bayram, D.V. 2019. Solving fractional Fredholm integro-differential equations by Laguerre polynomials. Sains Malaysiana 48(1): 251-257.

Ghazanfari, B., Ghazanfari, A.G. \& Veisi, F. 2010. Homotopy perturbation method for the nonlinear fractional Integrodifferential equations. Australian Journal of Basic and Applied Sciences 4: 5823-5829.

Haddadi, N., Ordokhani, Y. \& Razzaghi, M. 2012. Optimal control of delay systems by using a hybrid functions approximation. Journal of Optimization Theory and Applications 153: 338-356.

Huang, L., Li, X.F., Zhao, Y. \& Duan, X.Y. 2011. Approximate solution of fractional integro-differential equations by Taylor expansion method. Computers \& Mathematics with Applications 62: 1127-1134.

Keshavarz, E., Ordokhani, Y. \& Razzaghi, M. 2019. Numerical solution of nonlinear mixed Fredholm-Volterra integrodifferential equations of fractional order by Bernoull wavelets. Computational Methods for Differential Equations 7: 163-176

Kilbas, A.A., Srivastava, H.M. \& Trujillo, J.J. 2006. Theory and Applications of Fractional Differential Equations. San Diego: Elsevier.

Kurulay, M.t. \& Secer, A. 2011. Variational iteration method for solving nonlinear fractional integro-differential equations. International Journal of Computer Science and Emerging Technologies 2: 18-20.

Mashayekhi, S., Razzaghi, M. \& Wattanataweekul, M. 2016. Analysis of multi-delay and piecewise constant delay systems by hybrid functions approximation. Differential Equations and Dynamical Systems 24: 1-20.

Mashayekhi, S., Ordokhani, Y. \& Razzaghi, M. 2012. Hybrid functions approach for nonlinear constrained optimal control problems. Communications in Nonlinear Science and Numerical Simulation 17: 1831-1843.

Mashayekhi, S. \& Razzaghi, M. 2016. Numerical solution of the fractional Bagley-Torvik equation by using hybrid functions approximation. Mathematical Methods in the Applied Sciences 39: 353-365.

Mashayekhi, S. \& Razzaghi, M. 2015. Numerical solution of nonlinear fractional integro-differential equations by hybrid functions. Engineering Analysis with Boundary Elements 56: 81-89.

Meng, Z., Wang, L., Li, H. \& Zhang, W. 2015. Legendre wavelets method for solving fractional integro-differential equations. International Journal of Computer Mathematics 92: 12751291

Miller, K.S. \& Ross, B. 1993. An Introduction to the Fractional Calculus and Fractional Differential Equations. New York: Wiley.

Mittal, R.C. \& Nigam, R. 2008. Solution of fractional integro-differential equations by Adomian decomposition method. The International Journal of Applied Mathematics and Mechanics 4: 87-94

Momani, S. \& Noor, M.A. 2006. Numerical methods for fourthorder fractional integro-differential equations. Applied Mathematics and Computation 182: 754-760.

Nemati, S. \& Lima, P.M. 2018. Numerical solution of nonlinear fractional integro-differential equations with weakly singular kernels via a modification of hat functions. Applied Mathematics and Computation 327: 79-92.

Podlubny, I. 1999. Fractional Differential Equations. San Diego: Academic Press. 
Rahimkhani, P., Ordokhani, Y. \& Babolian, E. 2017. Fractionalorder Bernoulli functions and their applications in solving fractional Fredholem-Volterra integro-differential equations. Applied Numerical Mathematics 122: 66-81.

Rawashdeh, E.A. 2006. Numerical solution of fractional integrodifferential equations by collocation method. Applied Mathematics and Computation 176: 1-6.

Saadatmandi, A. \& Dehghan, M. 2011a. A Legendre collocation method for fractional integro-differential equations. Journal of Vibration and Control 17: 2050-2058.

Saadatmandi, A. \& Dehghan, M. 2011b. A tau approach for solution of the space fractional diffusion equation. Computers and Mathematics with Applications 62: 1135-1142.

Saadatmandi, A., Khani, A. \& Azizi, M.R. 2018. A sinc-GaussJacobi collocation method for solving Volterra's population growth model with fractional order. Tbilisi Mathematical Journal 11: 123-137.

Saeedi, H., Mohseni, M., Mollahasani, N. \& Chuev, G. 2011. A CAS wavelet method for solving nonlinear
Fredholm integro-differential equations of fractional order. Communications in Nonlinear Science and Numerical Simulation 16: 1151-1163.

Zhu, L. \& Fan, Q. 2012. Solving fractional nonlinear Fredholm integro-differential equations by the second kind Chebyshev wavelet. Communications in Nonlinear Science and Numerical Simulation 17: 2333-2341.

Department of Applied Mathematics

Faculty of Mathematical Sciences

University of Kashan

Kashan 87317-53153

Iran

*Corresponding author; email: saadatmandi@kashanu.ac.ir

Received: 31 May 2019

Accepted: 5 January 2020 